\title{
Facilitating Transfer of Training in NZ and Samoan Student Teachers
}

\author{
Lex McDonald \\ School of Education, Victoria University of Wellington \\ Rasela Tufue-Dolgoy \\ National University of Samoa
}

Initial teacher education is a complex multifaceted process with one of the pivotal components being transfer of the training. In the past, minimal attention has been given to how teacher educators interact with student teachers to facilitate implementation of ideas in the classroom. The purpose of this study was to explore teacher educators' knowledge of transfer of training as an approach to assisting student teachers achieve outcomes in the classroom. It was an exploratory qualitative study and 16 teacher educators (10 New Zealanders and 5 Samoan) were interviewed. The findings from the two sets of educators were similar but a few differences were noted. The teacher educators understood transfer as an important concept and practice involving a set of key players. They could not specifically link their practice to transfer theories, strategies or a strategic framework for implementation. Knowledge of transfer effectiveness and the means of evaluating its occurrence were largely unknown as was the literature on transfer barriers. Nevertheless, most could relate their approach to a transfer process and report successes but it was concluded that they were largely uninformed by the transfer of training literature. Implications for practice and the need for future research were outlined.

Keywords: teacher educators, student teachers, transfer of training, initial teacher education

Professional learning in initial teacher education (ITE) requires transfer of ideas and skills to the classroom. However, minimal attention has been directed to the use of transfer of training/learning research findings relating to teacher educators' approach to assisting the student teachers to use ideas/skills in the classroom. Teacher educators work in a range of contexts and, although this study is related to the initial teacher education context, the findings will have implications for these other contexts where the teacher educators work to link theory and practice. It is largely unknown what use of transfer of training (ToT) knowledge/strategies is made by teacher educators. Nevertheless, an emerging research agenda has been developed concerning the use of ToT in professional contexts, including teacher preparation. In this original glocal-oriented study, New Zealand and Samoan teacher educators were surveyed to identify their understandings of their knowledge and strategies that could be linked to the ToT and strategies used to prepare student teachers for their teaching experience.

\section{Transfer of Training: The role of the teacher educator}

Teacher preparation is varied, but in most countries the policy framework outlines that learning entails development of skills and knowledge in a tertiary setting, consolidated by 
practice in a classroom. In this paper, it is contended that the ToT literature can make contributions to this process as it is concerned with implementation of ideas. In understanding the teacher educator role in student teacher preparation for the classroom, the New Zealand Education Council (2015) noted it was a complex task involving a range of activities including preparation for teaching experience. Darling-Hammond and Bransford (2005) identified the role as one of the "most demanding kinds of professional preparation" with an important component being to "link theory and practice" (p. 441). Undoubtedly, these viewpoints are consistent in the Samoan context - although there is minimal policy documentation. Nevertheless, the practicum is highlighted in the Samoan National Teacher Development Framework (Samoan Ministry of Education, Sport and Culture, 2011) and the teacher educator is considered to have a pivotal role and responsibility to prepare the student teacher for classroom practice. It is clear then that in both countries, the teacher educator assumes an important role in preparing student teachers for their teaching experience. As indicated however, minimal research has been undertaken concerning the teacher educator's knowledge/use of ToT - an area that could contribute significantly to the understanding of how to promote professional practice implementation. The ToT literature (at times referred to transfer of learning or generalisation) can provide some general guidelines in the absence of specific research but increasingly ToT and professional preparation have been explored and are able to provide suggestions for practice. There is an urgent need to undertake ToT research as it relates to professional learning of teachers (McDonald, 2011).

In a recent report the New Zealand Education Review Office (2017) noted that ITE is identified as a complex process with a range of issues impacting upon the practice but one of the key considerations being linking of theory and practice. One aspect of this theory is practice link concerns the transfer and application of ideas etc to the school setting. There are several commentaries and research findings (including the ToT literature) that can provide insight into how this process can best proceed between the university and school contexts. Cameron and Baker (2004), investigating ITE (1993-2004) in New Zealand, found that little was known about how teacher educators contribute to the learning of student teachers and the acquisition of attributes necessary for practice, and urged that more research be undertaken. Indeed, Loughran (2013) has promoted the idea that more clarity was needed about the teacher educator role and recommended a teacher educators' pedagogy focussing on constant critique with attention given to the conceptual and empirical literature. He identifies that a simple modelling of skills etc is insufficient to prepare student teachers for the complexity of the classroom and that the voices of the student teachers were very important in promoting their development. The preferred approach for ITE highlights the role of the community of learners in promoting student teacher development, although it was over 20 years ago that Zeichner (1996) highlighted the importance of a collaborative environment for developing theory-practice links. In a more recent study, Cornu and Ewing (2008) discussed the participatory shared community of colleagues as a cornerstone approach and noted this structure as the beginning of a teacher's ongoing learning. Grudnoff (2011), like Loughran, in a New Zealand study emphasised the centrality of student teacher voice in establishing a collaborative membership, in place of the reliance upon modelling of the associate teacher's performance. Studies such as these are particularly important because they identify important themes of the theory to practice relationship: a clear understanding of the teacher educator's role, the importance of a collaborative approach, and the need for teacher educators' practice to be centred upon the research literature. The ToT literature also 
acknowledges these issues as being important and can provide an alternative supporting perspective to facilitate the student teacher's development.

Several ToT studies have been undertaken that explore and contribute to understanding the specifics of teacher educator promotion of student teacher implementation of ideas etc in the schools. For example, Markelz, Riden, and Scheeler (2017) have noted that generalisation is a missing link and Kretlow and Helf (2013) indicated that even if it does occur, fidelity is a problem. This is despite the recognition given to the importance of generalisation some 50 years ago (Bae, Wolf, \& Risley, 1968), and Engelmann (1988) demonstrated that less than $30 \%$ of the student teachers' learning actually transferred. This then begs the question - why is transfer not occurring? Markelz et al. argue that a key reason is the disconnect between university and classroom realities with minimal attention given to generalisation, whilst Gable (2014) discusses the predominance of a 'train and hope' paradigm overlooking generalisation training. Zeichner (2010) points out that teacher educators are often "not aware of what is known from research about how to support teacher learning and its transfer to the early years of teaching in the context of a universitybased teacher education program" (p. 481). To overcome this barrier, Scheeler, Budin and Markelz (2016) have developed a model concerned with generalising effective teaching skills in teacher preparation which includes the four steps of immediate feedback, mastery training, use of generalisation stratagems and performance feedback in classroom settings. In support of this, Hattie and Timperley (2007) have identified that the fourth step, performance feedback, is the critical influence on learning and achievement if effective instruction is given, but depending on its nature, it can have differential impact. Needless to say however, with an understanding of the ToT literature there is range of other considerations that can be used to facilitate the transferring of the learning.

\section{Transfer of Learning, Transfer of Training and Generalisation}

The central thesis of this paper is that the ToT literature can provide additional approaches to promoting student teacher application of learning ideas. Transfer of learning was first conceptualised over 100 years ago as a means of examining teaching practice and a debate centred upon two key contrasting approaches - Thorndike (1933) promoted the identical elements approach (emphasising the importance of similar elements in transfer) and the gestalt (highlighting transfer of a general skill from one context to another) was developed by Judd (1908). Later, researchers (e.g., Goldstein, 1974) adapted the concept and studied transfer to improve workplace training. A foundation for contemporary interest in transfer was advanced by Baldwin and Ford (1988) outlining a ToT framework model incorporating three phases - inputs (planning), learning, and retention - followed by outputs (generalisation and maintenance). In psychology, transfer has been investigated within the operant conditioning paradigm of B. F. Skinner highlighting generalisation "as a procedure that increases the likelihood of a target operant response [causing] an increase of other responses that resemble the target response" (Phelps, 2011, p. 1255). Recent developments in cognitive science have assisted to make the concept more meaningful (Royer, Mestre, \& Dufresne 2005) and emphasise the individual's mental models (of the real world) and comprehension and retention of ideas - an approach which today emphasises mental tasks and challenges such as constructivist learning, vicarious learning approaches, memory aids, self-management cueing, feedback mediation, and recall strategies. Nevertheless, since the 
adoption of the term transfer of training, there have been numerous discussions and debates about its definition, nature, occurrence, conceptual clarity and value, theoretical foundations, utility, how to achieve and measure it and identification of enablers and barriers (refer McDonald, 2016). Some commentators (e.g., Detterman \& Sternberg, 1993), however, dispute that ToT can be accomplished - but, given the use of evidence-based practices and a strategic plan, it is agreed by most (e.g., Daffron \& North, 2011) that ToT can be achieved.

Discussions and debates about the nature of ToT, including its relationship to transfer of learning, definition, theoretical basis, process or outcome orientation, strategies use, and occurrence, persist. The terms ToT and transfer of learning are often confused but ToT is best identified as a specific form of transfer of learning - it identifies a purposeful process designed to achieve certain outcomes. Although it is a concept disparaged by some because of its wrongly attributed association with technical training, it is an appropriate term to use as it is precise, and has a solid foundation in the psychological literature as well as other disciplines that imply application of ideas attained in formal learning to another context. Mostly, the term ToT has moved beyond the behaviouristic technicist usage and assumed a more pervasive respected position (refer Segers \& Gegenfurnter, 2013). Another wide-ranging discussion has concerned the definition of ToT. Blume, Ford, Baldwin, and Huang (2010), who acknowledge the importance of the transfer concept and generalisation, identify it as a cognitive process of generalisation process and maintenance of knowledge and skills acquired from formal learning. Billet (2013) is even more precise with his cognitive socio-cultural explanation of ToT which he defined as "individuals construing what is experienced, aligned and reconciled with what is known and then constructing a response, which is mediated interand intra-psychologically" (p. 6). This latter definition highlights the learning process mediated by social and cultural contributions embedded in communities of practice as discussed by Lave and Wenger (1991).

Another discussed issue relates to the importance of creating a strategic approach which is logical, coherent and integrated. Several commentators (e.g., Halpern \& Hakel, 2003) have noted, however, that such an approach already exists within the science of learning but needs operationalising. For example, Daffron and North (2011) have demonstrated, via case studies of medics, teachers, lawyers, adult educators etc how ToT can be achieved by emphasising the seven key interactive factors of careful planning, learner characteristics and motivational strategies, design and delivery, learning context, immediate application, workplace environment factors, and elimination of barriers. Using a cognitive framework, Grossman and Salas (2011) emphasised the importance of planning for trainee characteristics, design and the work environment. One particularly important advance has been the development of a learning transfer inventory following an extensive period of research by Bates, Holton, and Hatala (2012) and this has identified, via empirical studies, 16 key factors (categorised into three key dimensions of ability, motivation and workplace) that account for effective transfer of training/learning. It is clear that considerable research has now accrued about the adoption of a strategic approach to transfer providing planning frameworks and identification of useful strategies.

Accepting that all the key theories have a contribution to make to transfer (Haskell, 2001) implies that trainers/facilitators have access to a vast range of strategies - for example, reflexive low-road transfer can draw upon routine-based learning approaches, whereas mindful high-road transfer involves abstraction and connections of learning activities. This high-road low-road (sub)theory (Salomon \& Perkins, 1989) is a synthesis of the similar elements and gestalt approaches and useful in many contexts where routine and more 
complex learning opportunities are needed. In a departure from the classic explanations of transfer, Schwartz, Bransford, and Sears (2005) use gestalt and cognitive theory to promote the idea of preparation for future learning. This involves the capacity to learn new information, using resources effectively and innovatively, and inventing new strategies for learning and problem solving in practice later, an approach that has significant promise for professional learning and communities of learners.

Another issue concerns transfer outcomes with numerous studies revealing low rates. The significant study of Saks and Belcourt (2006) found that $38 \%$ of training was not transferred and Clarke's (2002) survey of professional learning studies noted much lower than expected transfer. Furthermore, little has been documented about what has been learned or transferred and the causes of the low incidence (Daffron \& North, 2011), despite the existence of explanatory evaluation frameworks. Two models regularly referred to are that of Kirkpatrick and Kirkpatrick (2006), and its modified version for the professional learning of teachers developed by Guskey (2002) who emphasised satisfaction, learning, school support and change, use of knowledge/skills and school student outcomes indices.

Recently the role of culture in transfer has been considered an important consideration in ToT (Sarkar-Barney, 2004) and some exploratory studies have now been undertaken. For example, McDonald (2001) identified the importance of collaboration, social support/relationships and resource availability in a study undertaken in the Cook Islands, and in a study undertaken in Korea, Lim (1999) identified the importance of language, social value differences, technical issues (e.g., the type of acceptable training programmes) and learning style differences as potentially important ToT mediating factors. McDonald (2014) has identified a specific cultural set of factors in the Transfer of Training Audit recommending these be considered for ToT planning.

In all the key reviews of ToT there is a detailing of the importance of the key players (learners, facilitator/trainer, colleagues, supervisors) and the contexts for transfer. Berry (2015) has highlighted that the trainer/facilitator often has limited knowledge of theory and strategies. Cheng and Ho (2001) added that they often use a trial and error approach and avoid adopting a strategic approach - this is not surprising for as Hutchins, Burke, and Bethelsen (2010) stated, web-sites or light-weight practitioner journals are used rather than research findings. As Baldwin, Ford, and Blume (2009) outline, it is necessary for facilitators to adopt an overall theory/practice approach utilising the detailed research findings. A followup of these findings is undertaken in this research. It was an investigation occurring in a New Zealand and Samoan university and was implemented to provide some further clarification of teacher educators' knowledge and use of strategies to prepare student teachers for teaching experience. It centred around the opportunity to expand and add to teacher educators' knowledge about facilitating application of ideas.

\section{Methodology}

This was a glocally-oriented study examining the knowledge and use of ToT by teacher educators - it was not a comparative study, but was designed 'to take the fish out of the water' to move beyond the familiar to broaden theory/practice (Blömeke \& Paine, 2008). The two universities were chosen because of the geographical location of the researchers and the availability of teacher educators, there being close links between the two universities that have somewhat parallel teacher education approaches of 1, 2 or 3 teacher preparation years 
interspersed with at least two teaching experiences per year. Purposeful sampling was used, the criterion being selection of teacher educators who had a minimum of both Masters and a teacher qualification and minimum of six years' school teaching experience and at least six years as a teacher educator. These participants had a range of specialisations across the early childhood-primary-secondary divisions and all were (or had recently been) engaged in visiting students during teaching experience. Sixteen participants were interviewed and although a small group, it was likely to be a sufficient number for saturation (Guest, Bunce, \& Johnson, 2016). All the teacher educators were voluntary, and were interviewed for 20-40 minutes by one interviewer each in Samoa and New Zealand. One face-to-face, semi-structured, audiorecorded individual interview was conducted in English with 10 New Zealand and 6 Samoan teacher educators ( 15 of the 16 being female). The following six open-ended questions were used to gather the data:

1. What is your understanding of 'Lecturer's Strategies that promote student teachers' application of ideas during teaching experience?'

2. What is transfer of training? (Probes - definition, significance, key roles, theories, outcome literature. Related to above question 1 if it was unknown)

3. What strategies/approaches do you use to promote the application of skills, knowledge and practices of student teachers when they are on teaching experience?

4. Where did you learn about these strategies? (Probes - colleagues, trial and error, research findings, other)

5. How do you know if the ideas are implemented? (Probes - student self-report, report of others, observations, assignments, others)

6. Can you identify barriers preventing student teachers' implementation of ideas during teaching experience?

A thematic analysis (Miles, Huberman, \& Saldana, 2013) was undertaken to categorise findings into themes. Trustworthiness was assured by a range of procedures including:

1. Utilisation of the researchers' academic, experiential and research backgrounds, both being ex-teachers, and currently involved in teaching experience;

2. Adoption of well-established research methods including face-to-face interviewing (King \& Horrocks, 2010) and thematic analysis;

3. Independent checking of the coding and thematic analysis by each researcher;

4. The researchers' familiarity of teacher education programmes and the university contexts;

5. Employment of a range of volunteer expert teacher educator informants;

6. Linking of the research literature with the findings; and

7. Use of descriptive dialogue.

The ethical guidelines of both universities for undertaking the research were adopted with anonymity, confidentiality, right of withdrawal, and intention to publish outlined. 


\section{Findings}

In this research, consideration was given to the teacher educators' knowledge of ToT and strategies for preparing student teachers for teaching experience. Most participants indicated an understanding of the nature of transfer, its importance and the need for strategies to achieve it - but specific transfer theories were mainly unknown, few used evidence-based practices from this literature base, a strategic approach was not acknowledged as important by most, and the range of ToT research/practice barriers was largely unknown. Feedback about transfer occurrence arose mainly from observation and anecdotal feedback comments. A feature of the findings was that there was a remarkable similarity of findings to many of the teacher educators. The findings have been categorised into themes.

\section{Centrality of ToT and key players}

The participants' definition/understanding of TOT was a significant issue to explore and most (but some requiring prompting) gave clear indications of it. All recognised it as a pivotal aspect in professional development. Typical comments were:

Everybody needs to understand that concept, .... that's the whole purpose of our training, able to learn, get the ideas and apply. (Sam1)

It's ideas they might learn in their coursework and putting them into practice. (NZ1)

Several teacher educators used examples to explain ToT while others used a more technical definition:

I would model the strategies, some effective strategies that I thought students would find helpful. (NZ8)

Lecturers prepare the students in terms of strategies, pedagogies and content to be applied. (Sam2)

In all the systematic reviews and commentaries about ToT, important roles and interactions are identified. Participants identified a range of the key players but some were identified as having a particularly significant role. Surprisingly, only a couple recognised the key role of the teacher educator. A few teacher educators detailed the importance of other personnel such as the programme designers, personnel from the Ministry, and community members. One New Zealand teacher educator also indicated the importance of the students' families who could influence classroom practice:

It includes the teacher educators, the students, it also includes their teacher mentors or associate teachers, the principals and wider staff members. (NZ1)

I think first most important person is the student. (Sam5)

Important are the program designers, the people who say this is the structure of the course ... placing students in a large lecture theatre to learn for instance. (NZ2) 


\section{Theoretical awareness and strategy choice}

When seeking information about specific ToT theories and principles, participants were unable to identify any key theories directly associated with ToT, although several New Zealand teacher educators made some pertinent comments about related concepts/theories such as situated learning, approximation of practice, reinforcement approaches, modelling, and reflection. One of the participants highlighted that several theories were important and another considered support as an important conceptual consideration:

It's a fusion of a lot of theories. (Sam1)

The underlying principle ... is the notion of being supported. (Sam3)

A fundamental part of the professional learning design is the strategies used to enable retention, facilitate implementation, and promote sustainability. All participants provided meaningful strategies to promote ToT but were not necessarily linked to the high-leverage evidence-based ToT literature. Emphasis was upon activity learning, relevancy, and promoting general conditions for learning. Only one of the participants identified a systematic approach incorporating strategies:

...hands on experiences ... with a lot of group work, peer work, practical... (Sam1)

I do a lot of work around [simulating] professional learning communities ... they practice a lot of the skills ... I use a case method ... work very collaboratively. (NZ10)

My 5 ideas are: win their hearts (e.g., make a personal connection), win their minds (e.g., give them a rational), support them with examples (e.g., use modelling), make sure they have personal ownership (e.g., ample opportunity to discuss) and accountability (e.g. tasks and assignments). (NZ7)

A related issue concerned the source of the teacher educators' ideas. It is acknowledged that teacher educators have a key role in introducing and supporting the implementation of ideas and hence the source of how they develop their knowledge/strategies was a key issue. Mostly, the participants recognised that their knowledge and skills arose from their own experience and/or personal research/study (which of course may have been research based):

An accumulation of experiences, like, I've been a teacher, ... a teacher educator, .... done a lot of reading, and ... a lot of observation ... so I can put all those things together. (NZ1)

...my training as a teacher, during professional development. (Sam6)

\section{Outcome literature and evaluation awareness}

An important finding related to the teacher educators' knowledge about outcome literature on interventions designed to implement on-the-job application. Most of the participants stated they were unaware of the ToT outcome research studies although a couple noted that there were difficulties and low rates of transfer. Some barriers to successful outcomes were noted as being sources of poor ToT: 
It's not really effective ... when they go out to the workplace, it's not really happening. (Sam3)

Literature [indicates it is mostly] ... ineffective ... tends to have a lot of power issues, students will often be trying very hard to please their associate teacher ... to get a good report. (NZ2)

Another query in learning transfer is how to evaluate the occurrence of the transfer and how its assessed impact of TOT was explored. Some deemed the observation visit as a key assessment tool. Other strategies included talking to the children, assessing the student teachers' assignments and use of anecdotal methods such as informal contacts and email. Evaluation frameworks were not used:

You observe them, secondly it is what they record in their teaching experience folders, the other is the debrief. (NZ2)

I will find out when I actually go supervise them, assess their lesson ... their display, and get the feedback from the associate teacher. (Sam4)

I talk to the children in the classroom. (Sam5)

\section{Recognition of barriers}

The participants were asked to identify barriers experienced in the transfer process. These can thwart effective transfer but knowledge of them can assist in developing preventative approaches. The responses were consistent with the ToT literature and centred around lack of student teacher understanding, class/school resistances (e.g., not liking change) and arrangements (e.g., lack of resources), associate teacher and others' opposition, lack of modelling, the student teachers themselves, the mismatch between expectations and classroom reality, and language issues. None of the participants discussed the importance of the anticipation of barriers or the need to develop plans to prevent barriers arising:

...the associate teacher ... saying "oh no this isn't appropriate here", or "I've never done that here." (NZ7)

...student teacher lack of understanding of the content... (Sam3)

Student teachers ... worried about their classroom management, and so that's one of the barriers of implementation. (NZ3)

...The people who are in the field, or support from me, if I'm not there to support them or mentor them ... it can be a barrier. (Sam3)

Several of the Samoan participants identified language as a barrier. Often a mixture of English and Samoan is used in the university and school settings and if student teachers were unable to understand English, transfer would likely fail:

[The English language] makes it really hard for the student teachers ... so that it makes a bit of a difficulty ... to get across their ideas, and strategies. (Sam5)

A few also commented upon relationships in the Samoan schools and the importance for transfer: 
If lack of support from the principal, then it won't happen ... I've had feedback from my students that support is not always the case. (Sam1)

The students sometimes don't have support or good relationships with the principal, associate teacher, etc which doesn't help. (Sam5)

From the data collected it became obvious that teacher educators did not have specific ToT theory and practice knowledge or were able to link to the extensive evidence-based data but this did of course indicate that ToT was not occurring. One Samoan participant noted after reflecting about the interview:

I think, people need to know the importance of ToT, the importance of not only learning the ideas but at the same time how to transfer, ... There needs to be some workshops and maybe more research in this area, so that people are aware of the importance... (Sam1)

Overall, the findings revealed that all teacher educators recognised the nature of transfer, its importance for the student teachers, and a range of key role players. However, most were not able to identify specific ToT theories, concepts, or key principles of practice although some identified related education theories and practices. Most could discuss the strategies to facilitate ToT but these were not linked to any transfer research literature. The general effectiveness of transfer was mostly unknown but some ways of evaluating it were identified, although there was no systematic approach to measurement of transfer. Barriers were identified mainly from personal experience.

\section{Discussion}

This research considered teacher educators' knowledge and use of ToT when preparing student teachers for teaching experience. The objective of the study was to ascertain what transfer strategies were being used and if the extensive literature on ToT was being utilised to develop approaches. Most participants had knowledge of ToT, its significance, could explain the practices used and outlined a range of potential barriers/enablers of implementation based upon their experiences. They had little knowledge of ToT theories, research or outcome literature and mostly outlined ad hoc strategies rather than a strategic research evidence-based framework. Needless to say, transfer may have been occurring but if teacher educators were more aware of the literature, implementation approaches may be more efficacious (Daffron \& North, 2011). The teacher educators' approach and role needs at least a rethink, something that has been argued for many years in the teacher education literature.

It is recognised that a strategic approach could assist teacher educators to facilitate ToT - for example, Daffron and North's (2011) praxis structure (with the emphasis on professional learning contexts) could provide a schema for developing a more integrated implementation. Furthermore, the findings of Scheeler et al. (2016) concerning generalisation and maintenance is a valuable approach using feedback pre- and post-teacher educator input, programming for generalisation (e.g., cueing) and mastery of specific skills; however, university clinical teaching programmes for student teachers can be problematic with the transition to large-lecture 
teaching. Nevertheless, it is likely that the community of learners would welcome professional development and learning opportunities concerning high leverage practices that cross the disciplinary divide and create realistic links between the university programmes and the realities of the school classrooms (Grossman, Hammerness, \& McDonald, 2009; Scheeler et al., 2016). This highlights several issues. For example, the ToT literature identifies at times that specific transfer of ideas etc can be planned for immediate application in the classroom, whilst at other times the broader 'preparation for future learning' approach can be adopted to assist with membership in a community of learners and strategic principled transfer at later times. Another high leverage issue is the importance attached to relational, social, and cultural factors - for example, the work of Bishop and Berryman (2009) identified this in their Teaching Profile whilst Hunter and Anthony's (2011) research with Pasifika school students highlighted participation and communication practices in mathematics teaching. Teacher educators can work with student teachers to promote approaches that effect change in the class by using such approaches.

ToT research highlights the importance of an effective, informed and collaborative relationship between the key players (Haskell, 2001) but this was not always experienced by the participants and a key concern was the unintentional subversion of the transfer process by the range of individuals. Sweezie (2017) noted that a disconnection between key players was a serious barrier for ToT. This accentuates the need for partnership between key actors but many participants discussed interaction/relationship problems. For example, it was recognised that the teacher educator had a diminished decision-making control over implementation in the school setting and this could risk the fidelity of the transfer, unless there was precise clear communication between all parties. The promotion of a robust community of learners' approach would provide opportunities to overcome these barriers.

Although it was not intended to undertake a comparative study, it was apparent that there was agreement on many of the issues explored in the two different university settings. The only factors of difference were issues of language and the more explicit noting of hierarchy and relationships in the Samoan setting. Overall, however, there was a remarkable similarity of response from all participants.

There are several implications arising from this study. Teacher educator acquaintance with the interdisciplinary findings on transfer can only be beneficial and with adaptation of the approaches to meet the needs of an educational professional learning context. There is growing professional learning ToT literature as well that can be utilised. The rigidity of thinking about ToT is limiting opportunities. Additionally, a strengthening of the professional interactions and understandings about teaching experience would be useful to enhance the ToT knowledge base. Additional research is needed, however, to provide a more comprehensive analysis of what is occurring - this current research was exploratory, limited in scope, had a small set of participants, and only gathered qualitative data. Future research could examine the perspectives of the other key actors and quantitative studies could assess the degree of transfer and the identification of the most useful strategies in these teacher educator settings.

The findings from this study have provided an analysis of how teacher educators perceive ToT and prepare student teachers for teaching experience. Although there are some individual differences, the findings indicated that teacher educators did not have knowledge and practices drawn from ToT theory/research findings but mainly used approaches drawn from experience and educational theory. This finding supports the international literature about the need for teacher educators to be more aware of transfer and utilise evidence-based 
findings from educational psychology and other related disciplines. Nevertheless, in this research some valuable data were obtained about current practices used by teacher educators and provided ideas for teacher educators to explore further. What is needed now is a consideration about the usefulness of the ToT literature in promoting transfer in teacher education settings.

\section{References}

Baldwin, T. T., \& Ford, J. (1988). ToT: A review and directions for future research. Personnel Psychology, 41(1), 63-105.

Baldwin, T., Ford, J., \& Blume, B. (2009). ToT 1988-2008: An updated review and agenda for future research. International Review of Industrial and Organizational Psychology 24, 41-70.

Bates, R., Holton III, E. F., \& Hatala, J. P. (2012). A revised learning transfer system inventory: Factorial replication and validation. Human Resource Development International, 15(5), 549-569.

Berry, J. (2015). Training intervention and training transfer: Have trainers really grasped the importance? Timeless Time. Retrieved from https://www.timelesstime.co.uk/whitepaper/importance-of-training-transfer/

Billett, S. (2013). Recasting transfer as a socio-personal process of adaptable learning. Educational Research Review, 8, 5-13.

Bishop, R., \& Berryman, M. (2009). The Te Kotahitanga effective teaching profile. Set: Research Information for Teachers, 2(2).

Blömeke, S., \& Paine, L. (2008). Getting the fish out of the water: Considering benefits and problems of doing research on teacher education at an international level. Teaching and Teacher Education, 24(8), 2027-2037.

Blume, B., Ford, J., Baldwin, T., \& Huang, J. (2010). ToT: A meta-analytic review. Journal of Management, 36(4), 1065-1105.

Cameron, M., \& Baker, R. (2004). Research on initial teacher education in New Zealand. Wellington: New Zealand Council for Educational Research.

Cheng, E., \& Ho, D. (2001). A review of ToT studies in the past decade. Personnel Review, $30(1), 102-118$.

Clarke, N. (2002). Job/work environment factors influencing training transfer within a human service agency: Some indicative support for Baldwin and Ford's transfer climate construct. International Journal of Training and Development, 6(3), 146-162.

Cornu, R., \& Ewing, R. (2008). Reconceptualising professional experiences in pre-service teacher education ... reconstructing the past to embrace the future. Teaching and Teacher Education, 24(7), 1799-1812.

Daffron, S. R., North, M. W. (2011). Successful transfer of learning. Malabar, FA: Krieger.

Darling-Hammond, L., \& Bransford, J. (2005). Preparing teachers for a changing world: What teachers should learn and be able to do. San Francisco, CA: John Wiley.

Detterman, D. K., \& Sternberg, R. J. (1993). Transfer on trial: Intelligence, cognition, and instruction. Norwood, NJ: Ablex.

Education Review Office. (2017). Newly graduated teachers: Preparation and confidence to teach. Wellington, NZ: Author. 
Engelmann, S. (1988). The logic and facts of effective supervision. Education and Treatment of Children, 11(4), 328-340.

Goldstein, I. L. (1974). Training: Program development and evaluation. Monterey, CA: Brooks/Cole.

Grossman, P., Hammerness, K., \& McDonald, M. (2009). Redefining teaching, re-imagining teacher education. Teachers and Teaching: Theory and Practice, 15(2), 273-289.

Grossman, R., \& Salas, E. (2011). The ToT: What really matters. International Journal of Training and Development, 15(2), 103-120.

Grudnoff, L. (2011). Rethinking the practicum: Limitations and possibilities. Asia-Pacific Journal of Teacher Education, 39(3), 223-234.

Guest, G., Bunce, A., \& Johnson, L. (2006). How many interviews are enough? An experiment with data saturation and variability. Field Methods, 18(1), 59-82. doi:10.1177/1525822X05279903

Guskey, T. R. (2002). Does it make a difference? Evaluating professional development. Educational Leadership, 59(6), 45.

Halpern, D. F., \& Hakel, M. D. (2003). Applying the science of learning to the university and beyond: Teaching for long-term retention and transfer. Change: The Magazine of Higher Learning, 35(4), 36-41.

Haskell, R. (2001). Transfer of learning: Cognition, instruction and reasoning. San Diego, CA: Academic Press.

Hunter, R., \& Anthony, G. (2011). Forging mathematical relationships in inquiry-based classrooms with Pasifika students. Journal of Urban Mathematics Education, 4(1), 98119.

Hutchins, H., Burke, L., \& Berthelsen, A. (2010). A missing link in the transfer problem? Examining how trainers learn about training transfer. Human Resource Management 49(4), 599-618.

Judd, C. (1908). The relation of special training and general intelligence. Education Review, $36,42-48$.

King, N., \& Horrocks, C. (2010). Interviews in qualitative research. London: Sage.

Kirkpatrick, D., \& Kirkpatrick, J. D. (2006). Evaluating training programs: The four levels. San Francisco: Berrett-Koehler.

Kretlow, A., \& Helf, S. (2013). Teacher implementation of evidence-based practices in tier 1: A national survey. Teacher Education and Special Education, 36(3), 167-185.

Lave, J., \& Wenger, E. (1991). Situated learning: Legitimate peripheral participation. New York: Cambridge University Press.

Lim, D. H. (1999). Organizational and cultural factors affecting international ToT. Performance Improvement, 38(3), 30-36.

Loughran, J. (2013). Developing a pedagogy of teacher education: Understanding teaching \& learning about teaching. NY: Routledge.

Markelz, A., Riden, B., \& Scheeler, M. C. (2017). Generalization training in special education teacher preparation: Does it exist? Teacher Education and Special Education, 40(3), 179-163. Doi 0888406417703752.

McDonald, B. L. (2001). Transfer of training in a cultural context: A Cook Islands study. (Unpublished doctoral diss.). Victoria University of Wellington, New Zealand.

McDonald, L. (2011, December). Professional development and transfer of learning: Two sides of the same coin? Paper presented at the Fourth Educational Psychology Forum, Albany, Auckland, New Zealand. 
McDonald, L. (2014). Planning for impact: Transfer of training audit. Procedia-Social and Behavioral Sciences, 141, 129-137.

McDonald, L. (2016). Up the creek without a paddle? Professional development facilitators and transfer of training. EDULEARN16 Proceedings (pp. 7979-7987). 8th International Conference on Education and New Learning Technologies, Barcelona, Spain. Valencia, Spain: IATED. doi: 10.21125/edulearn.2016

Miles, M. B., Huberman, A. M., \& Saldana, J. (2013). Qualitative data analysis. Beverly Hills, CA: Sage.

New Zealand Education Council. (2015). Approval, review and monitoring processes and requirements for initial teacher education programmes. Wellington, NZ: Author.

Phelps, B. (2011). Response generalisation. In S. Goldstein \& J. Naglieri (Eds.), Encyclopedia of child behavior and development (pp. 1255-1256). New York: Springer.

Royer, J. M., Mestre, J. P., \& Dufresne, R. J. (2005). Introduction. Framing the transfer problem. Transfer of learning: From a modern multidisciplinary perspective. Greenwich, CT: Information Age.

Saks, A., \& Belcourt, M. (2006). An investigation of training activities and transfer of training in organizations. Human Resource Management, 45(4), 629-648. doi: 10.1002/hrm.20135

Salomon, G., \& Perkins, D. N. (1989). Rocky roads to transfer: Rethinking mechanism of a neglected phenomenon. Educational Psychologist, 24(2), 113-142.

Samoan Ministry of Education, Sport and Culture. (2011). National teacher development framework. Retrieved from .http://wbgfiles.worldbank.org/documents/hdn/ed/saber/supporting_doc/EAP/Samo a/SAA/MESC_2011_National_Teacher_Development_Framework.pdf

Sarkar-Barney, S. (2004). The role of national culture in enhancing training effectiveness: A framework. In M. Kaplan (Ed.), Cultural ergonomics (pp. 183-214). Amsterdam: Elsevier.

Scheeler, M. C., Budin, S., \& Markelz, A. (2016). The role of teacher preparation in promoting evidence-based practice in schools. Learning Disabilities - A Contemporary Journal, 14(2), 171-187.

Schwartz, D. L., Bransford, J. D., \& Sears, D. (2005). Efficiency and innovation in transfer. In D. Mestre (Ed.), Transfer of learning from a modern multidisciplinary perspective (pp. 1-51). CT: Information Age.

Segers, M., \& Gegenfurnter, A. (Eds.). (2013). Special Issue: Transfer of training: New conceptualizations through integrated research perspectives. Educational Research Review, 8.

Sweezie, J. (2017). Maximising learning transfer. Available from: http://www.fka.com/maximizing-learning-transfer/

Thorndike, E. L. (1933). A proof of the law of effect. Science, 77(1989), 173-175.

Zeichner, K. (1996). Designing educative practicum experiences for prospective teachers. In K. Zeichner, S. Melnick, \& M. L. Gomez (Eds.). Currents of reform in pre-service teacher education (pp. 215-234). New York: Teachers College Press.

Zeichner, K. (2010). Rethinking the connections between campus courses and field experiences in college-and university-based teacher education. Journal of Teacher Education, 61(1-2), 89-99. 
Lex McDonald is a senior lecturer in the Faculty of Education at Victoria University of Wellington, NZ. He has been a teacher and practising psychologist and at present his current position is concerned with training educational psychologists. His interests include training, professional development and learning and inclusive education.

Email: lex.mcdonald@vuw.ac.nz

Rasela Tufue-Dolgoy is a senior lecturer in the Faculty of Education at the National University of Samoa and has interests in teaching and learning, initial teacher education, teacher professional development and learning and inclusive education. Rasela was a teacher in Samoa prior to moving to the university.

Email: r.tufue-dolgoy@nuw.edu.ws 